\title{
Immunization status of patients with inflammatory bowel disease
}

\author{
Karin Lye auf der STRASSE, Carmen Mayanna JAMUR, Janaina MARQUES, Mirian Su Mi KIM, \\ Ricardo Rasmussen PETTERLE and Heda Maria Barska dos Santos AMARANTE
}

Received 13/10/2018 Accepted 14/5/2019

\begin{abstract}
Background - Treatment for inflammatory bowel disease (IBD) includes a variety of immunosuppressants and biological agents, which increase the risk of infections due to altered cellular and humoral immunity. Prevention of these infections can be done through vaccination, however, patients with IBD are usually under-immunized. Objective - Analyze the immunization status of patients with IBD and confront it with the current recommendations to verify if the immunization guidelines are being followed correctly. Methods - Analytical cross-sectional study including 239 IBD patients being regularly followed in the Gastroenterology Service from Hospital de Clinicas da Universidade Federal do Paraná, which were subjected to a survey about their relevant demographic data and immunization status. Results - The amount of patients that declared being unaware of their immunization status is high - between 34.3\% (Tdap) and 52\% (meningococcal) - excepting IIV, hepatitis B and HPV. The vaccines with the largest rates of patients declaring to have taken it are inactivated influenza vaccine (72.4\%), BCG $(55.3 \%)$, hepatitis B $(48.3 \%)$, measles, mumps and rubella vaccine $(43.8 \%)$ and DTaP $(43 \%)$. The vaccines with the lowest rates of patients declaring to have taken it are Haemophilus influenza type b (0.8\%), herpes zoster (2.1\%) and HPV (3.4\%). Patients that are being treated or have been treated with biological therapy have the largest immunization coverage for inactivated influenza vaccine (81\%) and PPSV23 (25.9\%), also they have the largest awareness rates for those vaccines. Conclusion - Although being a specialized service linked to a university hospital, vaccination coverage and patients' awareness rates proved to be below the desirable level. Vaccination and recovery of the immunization history is recommended immediately after the diagnosis of IBD, regardless of the use of biological agents. Those findings support the need of implementing hospital guidelines and constantly verifying its application by the multidisciplinary team in specialized services in IBD.
\end{abstract}

HEADINGS - Inflammatory bowel diseases. Crohn disease. Proctocolitis. Vaccination, therapeutic use. Immunization.

\section{INTRODUCTION}

Inflammatory bowel disease (IBD), consisting of Crohn's disease $(\mathrm{CD})$ and ulcerative colitis $(\mathrm{UC})$, results from an uncontrolled immune-mediated inflammatory response to an unknown environmental factor that interacts with the intestinal microbiota in genetically predisposed patients ${ }^{(1)}$. This leads to symptoms such as diarrhea, abdominal pain in colic and, more rarely, complications such as toxic megacolon ${ }^{(2)}$.

Effective treatment for IBD includes a variety of immunosuppressants and biological agents, which increases the risk of infections $^{(3)}$ due to altered cellular and humoral immunity ${ }^{(4)}$. Prevention of these infections can be done through vaccination, however, patients with IBD are usually under-immunized ${ }^{(3)}$. Some of the contributing factors are lack of awareness about the importance of vaccination, misperception about the safety of vaccines in immunocompromised patients, fear of side effects, the uncertain role of the gastroenterologist in contrast to the primary care physician ${ }^{(5)}$ and the lack of knowledge by the gastroenterologists about the appropriate immunization for IBD patients ${ }^{(3)}$.

There is great benefit in vaccinating IBD patients, including those undergoing immunosuppressive therapy; the efficacy of the immunization can be verified by antibody titration ${ }^{(5,6)}$. However, patients receiving biological agents may have a suboptimal response to vaccines due to treatment with anti-TNF or to disease activity, which can lead to low vaccine response in severe cases $^{(7)}$.

Immunocompetent patients with IBD may be vaccinated with standard vaccination recommendations. Patients with IBD who will use immunosuppressive therapy should follow special considerations $^{(5)}$.

The most appropriate measure - according to European Crohn's and Colitis Organization's Second Consensus - to prevent, diagnose and manage the risk of infections in IBD patients is to consider the vaccination program for all patients soon after the diagnosis of IBD, since most will be treated with some immunosuppressive $\operatorname{drug}^{(4)}$. Thus, in a first contact with the patient, the history of the vaccines must be collected and recorded to serve as a guide for immunization orientation. The recommended schedule for IBD patients includes: tetanus, diphtheria, poliovirus, varicella, human papillomavirus (HPV), influenza, pneumococcal vaccines and hepatitis $\mathrm{B}^{(4)}$. It is important to note that vaccines with live antigens are contraindicated to those patients ${ }^{(5)}$.

The objective of this study is to analyze the immunization status of patients with IBD and to compare it with the current literature

Declared conflict of interest of all authors: The authors of this study declare no competing interests.

Disclosure of funding: no funding received.

Universidade Federal do Paraná, Hospital de Clínicas, Departamento de Gastroenterologia, Curitiba, PR, Brasil.

Corresponding author: Heda Maria Barska dos Santos Amarante. E-mail: hedaamarante@gmail.com 
recommendation to verify if immunization guidelines are being correctly applied in this population. Based on the findings, a clinical protocol for evaluation and recommendation of immunization for patients with IBD may be proposed, especially for the portion of the IBD population that uses the SUS (Brazil's universal healthcare system) as the main health service.

\section{METHODS}

Cross-sectional epidemiological study conducted with IBD patients in the Gastroenterology Service of the Hospital de Clinicas da Universidade Federal do Paraná (HC-UFPR). This study was approved by the Human Research Ethics Committee of HC-UFPR on June 12th, 2015, under the CAAE identification: 46169815.3.0000.0096.

From July 2015 to June 2016, 239 IBD patients from HC-UFPR were submitted to a questionnaire about relevant demographic data and vaccination history (vaccinated, non-vaccinated or not sure), with the aim to analyze the immunization status of this population for the following vaccines: inactivated influenza vaccine (IIV), 13-valent pneumococcal conjugate vaccine (PCV13), 23-valent pneumococcal polysaccharide vaccine (PPSV23), tetanus toxoid, reduced diphtheria toxoid and acellular pertussis vaccine (Tdap), Haemophilus influenza type b (Hib), hepatitis A (HepA), hepatitis B (HepB), serogroups A, C, W and Y meningococcal vaccine (MenACWY), varicella (VAR), rubella, recombinant zoster vaccine (RZV), measles, mumps and rubella vaccine (MMR), diphtheria, tetanus and acellular pertussis vaccine (DTaP), HPV and BCG. Inclusion criteria of patients were: having a confirmed diagnosis of IBD (CD or UC), being followed up at the specialized outpatient clinic from HC-UFPR and having properly filled out the Informed Consent Form.

The collected data were inserted in an electronic spreadsheet (Microsoft Excel ${ }^{\circledR}$ ), checked and exported for later statistical analysis. The results of the study were expressed in absolute and relative frequencies for qualitative variables and mean and standard deviation (SD) or median (Md) and interquartile range (IQR) for the quantitative variables. To compare qualitative variables between groups, Fisher's Exact Test or the Chi-square Test were used when possible. For the comparison between three or more groups, the non-parametric Kruskal-Wallis Test was used, and the Conover Test with Bonferroni correction was used for multiple comparisons. Relevant results taken in consideration were those with $P<0.05$. All data analysis was done in statistical software R, version $3.4 .0^{(8)}$.

\section{RESULTS}

Of the 239 patients interviewed (estimated as $30 \%$ of the total number of patients enrolled in the outpatient clinic), the majority were women $(63.6 \%)$, with a mean age of 46.4 years $(\mathrm{SD}=12.7)$. The majority of the patients reported being married (54\%), being white $(72 \%)$, having educational level up to High School (82\%) and currently being employed $(50.6 \%)$.

Regarding the clinical history (TABLE 1), the average BMI was $25.6(\mathrm{SD}=4.7)$ and the majority of patients were diagnosed with $\mathrm{CD}(57.8 \%)$ and never received treatment with biological agents $(74.9 \%)$. Of the 60 patients interviewed who are receiving or have already received treatment with biological agents, $58(96.6 \%)$ have a diagnosis of $\mathrm{CD}$ and $2(3.33 \%)$ have a diagnosis of UC.
TABLE 1. Demographic and clinical data of study population $(n=239)$.

\begin{tabular}{lc}
\hline & $\mathbf{n}(\%)$ \\
\hline Gender & $152(63.6)$ \\
Female & $87(36.4)$ \\
Male & $46.4 \pm 12.7$
\end{tabular}

$\begin{array}{lc}\text { Civil status } & \\ \text { Single } & 65(27.2) \\ \text { Married } & 129(54.0) \\ \text { Widowed } & 11(4.6) \\ \text { Divorced } & 16(6.7) \\ \text { Separated } & 11(4.6) \\ \text { Stable union } & 7(2.9) \\ & \\ \text { Ethnicity } & \\ \text { White } & 172(72.0) \\ \text { Black } & 24(10.0) \\ \text { Mixed } & 40(16.7) \\ \text { Asian } & 3(1.3)\end{array}$

Educational attainment

$\begin{array}{lc}\text { Illiterate } & 5(2.1) \\ \text { Incomplete primary education } & 55(23.0) \\ \text { Primary education } & 36(15.1) \\ \text { Incomplete secondary education } & 13(5.4) \\ \text { Secondary education } & 87(36.4) \\ \text { Incomplete graduate education } & 16(6.7) \\ \text { Graduate education } & 19(7.9) \\ \text { Postgraduate education } & 8(3.4)\end{array}$

Employment

Yes

No

$118(49.4)$

Household income, mean \pm SD

$2.59 \pm 1.88$

$\begin{array}{ll}\text { Diagnosis } & \\ \text { Ulcerative colitis } & 101(42.2) \\ \text { Crohn's disease } & 138(57.8) \\ \text { BMI, mean } \pm \text { SD } & 25.6 \pm 4.7\end{array}$

Biological therapy for IBD

$\begin{array}{ll}\text { No } & 179(74.9)\end{array}$

$\begin{array}{ll}\text { Yes } & 60(25.1)\end{array}$

SD: standard deviation, IBD: inflammatory bowel disease. 


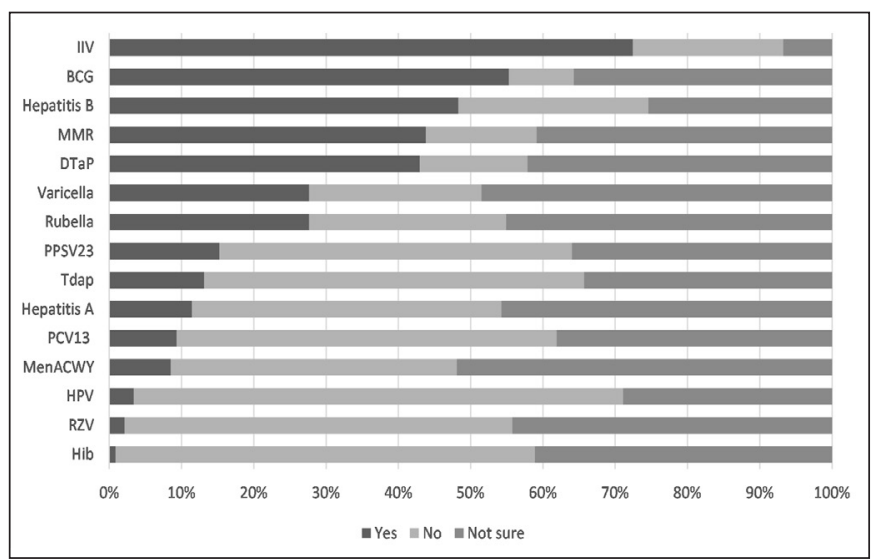

FIGURE 1. Immunization status of study population.

Regarding the vaccination status (FIGURE 1), the rate of patients reported to be unaware was high - between 34.3\% (Tdap) and $52 \%$ (MenACWY) - with the exception of IIV (6.8\%), HepB $(25.4 \%)$ and HPV (29\%). The vaccines with the highest rate of patients reporting to have received the vaccine were IIV $(72.4 \%)$, BCG (55.3\%), HepB (48.3\%), MMR (43.8\%) and DTaP (43\%). The vaccines with the lowest rate of patients reporting to have received the vaccine were Hib (0.8\%), RZV (2.1\%) and HPV (3.4\%).

When analyzing the vaccination status according to the diagnosis (FIGURE 2), statistically significant difference was observed for PCV13 $(P=0.138)$, Tdap $(P=0.0170)$ and HepB $(P=0.0127)$, in which the rate of $\mathrm{CD}$ patients who reported having received the vaccine is higher than that of $\mathrm{UC}$ patients. $14 \%$ of $\mathrm{CD}$ patients reported having received PCV13 against 3\% of UC patients, $18.4 \%$ of $\mathrm{CD}$ patients reported having received the Tdap vaccine against $6.1 \%$ of UC patients and $55.9 \%$ of $\mathrm{CD}$ patients reported having received HepB against $37.4 \%$ of UC patients.

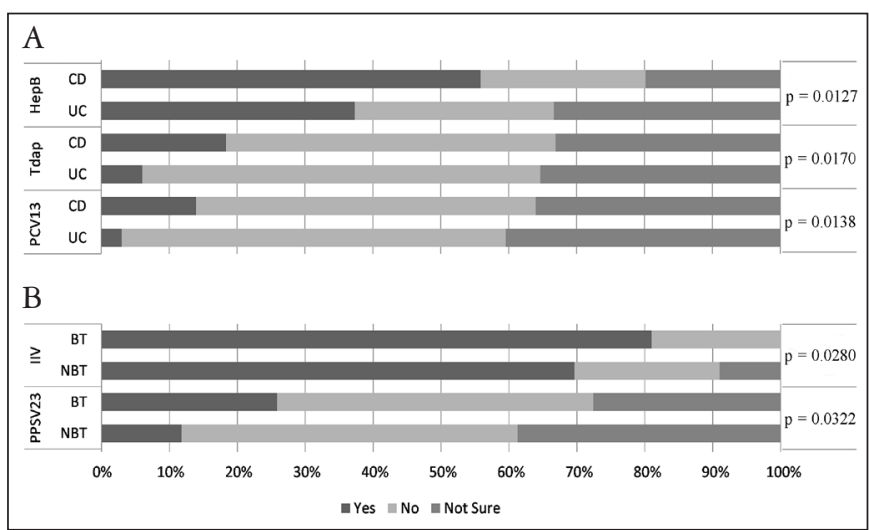

FIGURE 2.A. Immunization status according to diagnosis. CD: Crohn's disease; UC: ulcerative colitis. B. Immunization status according to type of treatment. BT: biological therapy; NBT: non-biological therapy.

There was no statistically significant difference in the reported vaccination status between $\mathrm{UC}$ and $\mathrm{CD}$ patients for the following vaccines: IIV, PP23V, Hib, HepA, MenACWY, VAR, Rubella, RZV, MMR, DTaP, HPV and BCG (TABLE 2).

When analyzing the reported vaccination status according to the type of treatment received (FIGURE 2), a statistically significant difference was observed in IIV $(P=0.0280)$ and PP23V $(P=0.0322)$. Immunization coverage is higher among the patients who are currently being treated or have been treated with biological agents in the past for IIV $(81 \%)$ and PP23V $(25.9 \%)$ than among those who have never received biological agents before $(69.7 \%$ and $11.8 \%$ respectively). Patients who are currently being treated or have already been treated with biological agents before are more aware of their vaccination status for IIV (100\%) and PP23V $(72.5 \%)$ than those who have never been treated with biological agents before $(91 \%$ and $61.2 \%$ respectively).

TABLE 2. Immunization status according to diagnosis, n (\%).

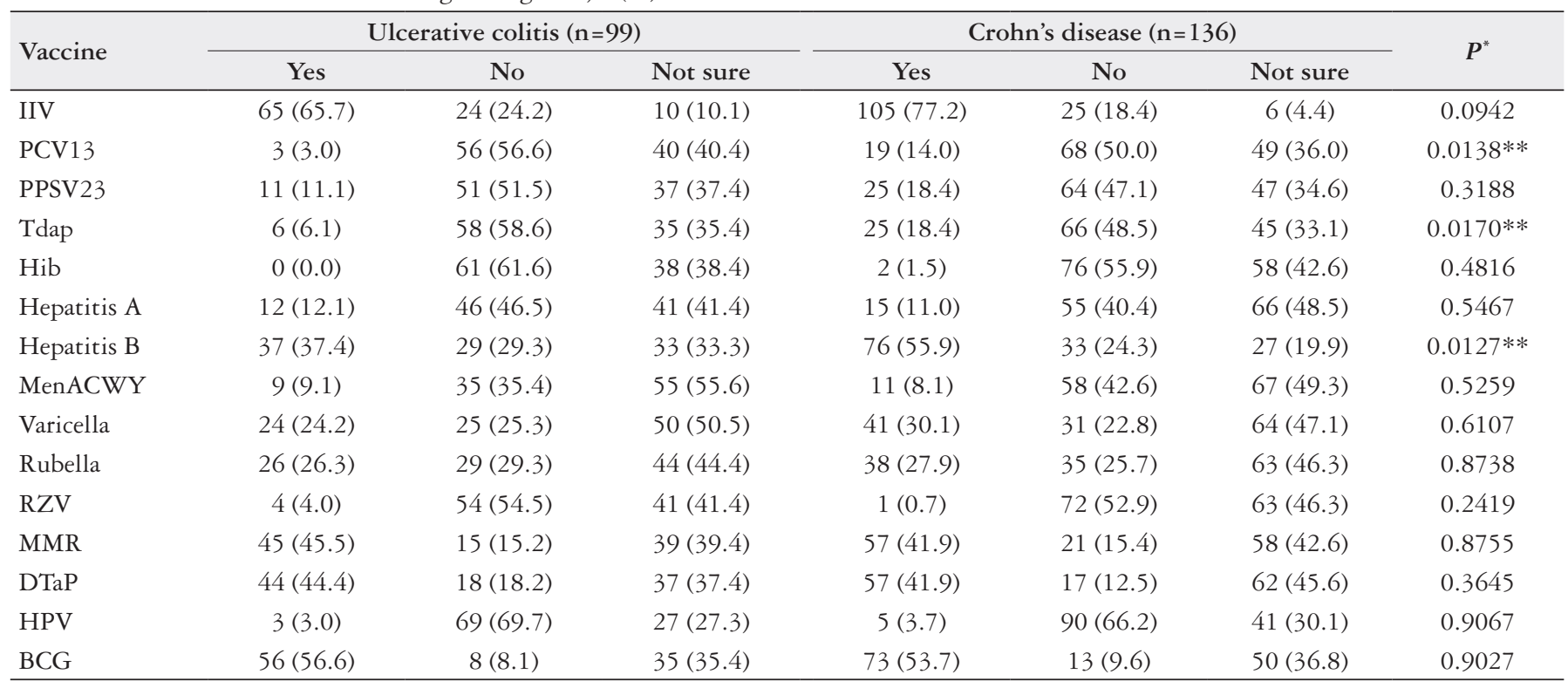

IIV: inactivated influenza vaccine; PCV13: 13-valent pneumococcal conjugate vaccine; PPSV23: 23-valent pneumococcal polysaccharide vaccine; Tdap: tetanus toxoid, reduced diphtheria toxoid and acellular pertussis vaccine; Hib: Haemophilus influenza type b; MenACWY: serogroups A, C, W and Y meningococcal vaccine; RZV: recombinant zoster vaccine; MMR: measles, mumps and rubella vaccine; DTaP: diphtheria, tetanus and acellular pertussis vaccine. *Fisher's exact test. $* * P<0.05$. 
There was no statistically significant difference in the reported vaccination status between patients who are or have been treated with biological agents and those who have never been treated with biological agents in: PCV13, Tdap, Hib, HepA, HepB, MenACWY, VAR, Rubella, RZV, MMR, DTaP, HPV and BCG (TABLE 3).
When analyzing the association between income (in amount of minimum wages) and reported vaccination status for each of the vaccines (TABLE 4), a statistically significant difference was observed in Hib $(P<0.001)$, HepA $(P=0.0021)$, HepB $(P=0.0061)$, $\operatorname{MenACWY}(P=0.0157), \operatorname{VAR}(P=0.0246)$ and $\operatorname{DTaP}(P=0.0452)$.

TABLE 3. Immunization status according to type of treatment, n (\%).

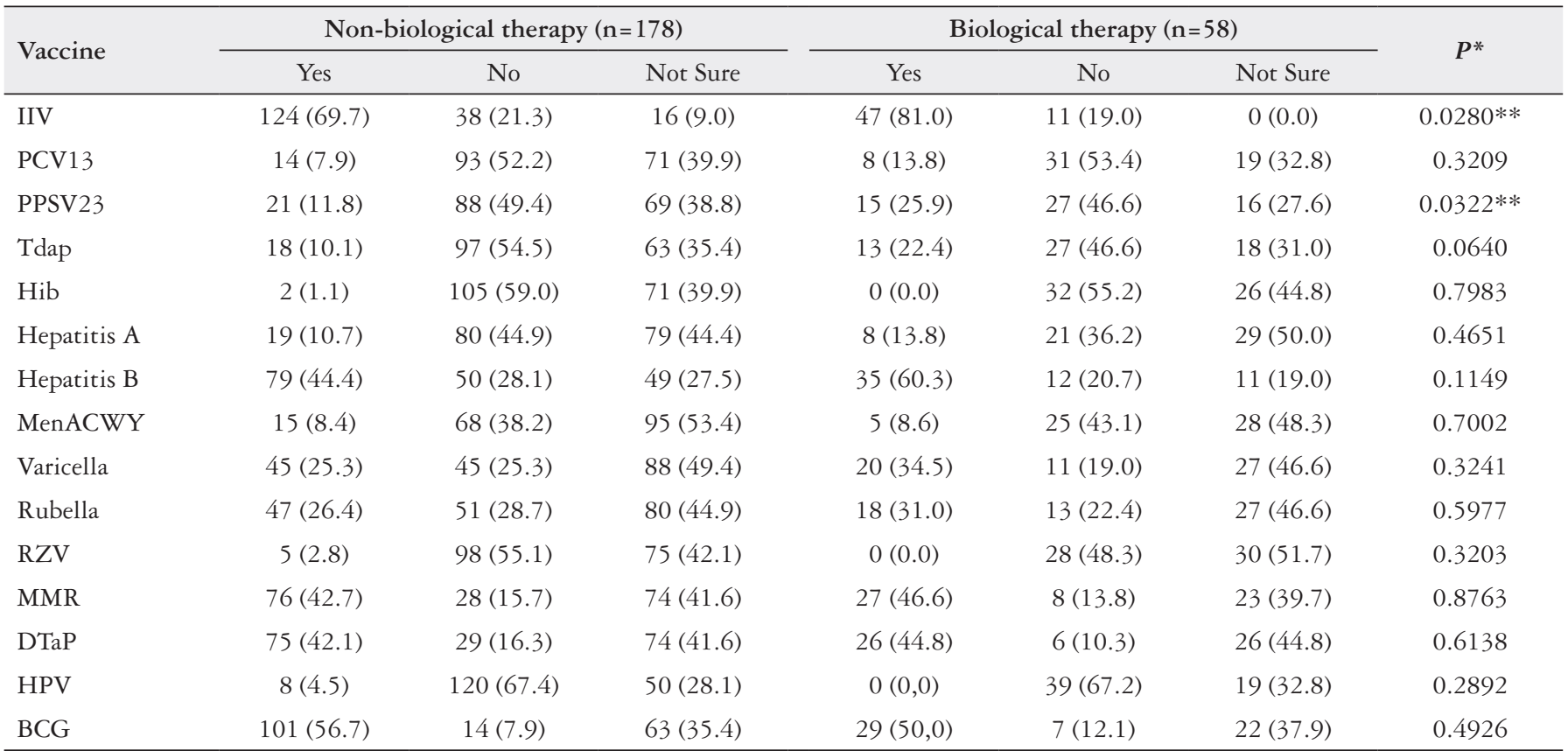

IIV: inactivated influenza vaccine; PCV13: 13-valent pneumococcal conjugate vaccine; PPSV23: 23-valent pneumococcal polysaccharide vaccine; Tdap: tetanus toxoid, reduced diphtheria toxoid and acellular pertussis vaccine; Hib: Haemophilus influenza type b; MenACWY: serogroups A, C, W and Y meningococcal vaccine; RZV: recombinant zoster vaccine; MMR: measles, mumps and rubella vaccine; DTaP: diphtheria, tetanus and acellular pertussis vaccine. *Fisher's exact test. $* * P<0.05$.

TABLE 4. Household income (in minimum wage numbers) according to immunization status, Md (IQR).

\begin{tabular}{lcccc}
\hline Vaccine & Yes & No & Not sure & \multicolumn{1}{c}{$P^{*}$} \\
\hline IIV & $2.0(1.5-3.0)$ & $2.0(1.5-3.0)$ & $3.0(1.9-3.0)$ & 0.5021 \\
PCV13 & $2.0(1.0-3.0)$ & $2.0(1.0-3.0)$ & $2.0(1.5-3.0)$ & 0.1593 \\
PPSV23 & $2.0(1.4-3.0)$ & $2.0(1.0-3.0)$ & $2.0(1.5-3.0)$ & 0.1296 \\
Tdap & $2.0(1.5-3.3)$ & $2.0(1.0-3.0)$ & $2.0(1.5-3.0)$ & 0.1158 \\
Hib & $10.0(7.5-12.5)$ & $2.0(1.0-3.0)$ & $2.5(1.5-3.5)$ & $<0.001 * *$ \\
Hepatitis A & $2.0(1.5-3.3)$ & $2.0(1.0-3.0)$ & $2.5(1.5-4.0)$ & $0.0021^{* *}$ \\
Hepatitis B & $2.0(1.5-3.0)$ & $2.0(1.0-2.5)$ & $3.0(1.5-4.0)$ & $0.0061 * *$ \\
MenACWY & $2.0(1.9-3.1)$ & $2.0(1.0-3.0)$ & $2.2(1.5-3.5)$ & $0.0157 * *$ \\
Varicella & $2.0(1.0-2.5)$ & $2.0(1.0-3.0)$ & $2.5(1.5-3.9)$ & $0.0246 * *$ \\
Rubella & $2.0(1.0-2.5)$ & $2.0(1.5-3.0)$ & $2.5(1.5-3.9)$ & 0.0965 \\
RZV & $2.0(1.0-3.0)$ & $2.0(1.5-3.0)$ & $2.2(1.5-3.1)$ & 0.2898 \\
MMR & $2.0(1.5-3.5)$ & $2.0(1.0-2.5)$ & $2.0(1.4-3.0)$ & 0.0998 \\
DTaP & $2.0(1.5-3.0)$ & $2.0(1.0-2.5)$ & $2.0(1.5-3.0)$ & $0.0452^{* *}$ \\
HPV & $2.0(1.5-2.0)$ & $2.0(1.0-3.0)$ & $2.5(1.9-3.0)$ & 0.1570 \\
BCG & $2.0(1.0-3.0)$ & $2.0(1.5-3.0)$ & $2.0(1.5-3.0)$ & 0.4223 \\
\hline
\end{tabular}

Md: median; IQR: interquartile range; IIV: inactivated influenza vaccine; PCV13: 13-valent pneumococcal conjugate vaccine; PPSV23: 23-valent pneumococcal polysaccharide vaccine; Tdap: tetanus toxoid, reduced diphtheria toxoid and acellular pertussis vaccine; Hib: Haemophilus influenza type b; MenACWY: serogroups A, C, W and Y meningococcal vaccine; RZV: recombinant zoster vaccine; MMR: measles, mumps and rubella vaccine; DTaP: diphtheria, tetanus and acellular pertussis vaccine. $*$ Kruskal-Wallis. $* * P<0.05$. 
Those who received Hib had a higher income $(\mathrm{Md}=10.0 / \mathrm{IQR}=7.5-$ 12.5) than those who reported not having received $(\mathrm{Md}=2.0 /$ $\mathrm{IQR}=1.0-3.0)$ or not knowing $(\mathrm{Md}=2.5 / \mathrm{IQR}=1.5-3.5)$. Those who reported not knowing whether they received HepA had higher income $(\mathrm{Md}=2.5 / \mathrm{IQR}=1.5-4.0)$ than those who reported having received $(\mathrm{Md}=2.0 / \mathrm{IQR}=1.5-3.3)$ or $\operatorname{not}(\mathrm{Md}=2.0 / \mathrm{IQR}=1.0-3.0)$. Those who reported not knowing whether they received HepB had a higher income $(\mathrm{Md}=3.0 / \mathrm{IQR}=1.5-4.0)$ than those who reported having received $(\mathrm{Md}=2.0 / \mathrm{IQR}=3.0)$ or not $(\mathrm{Md}=2.0$ / $\mathrm{IQR}=1.0-2.5$ ).

Those who reported not knowing whether they received MenACWY had a higher income $(\mathrm{Md}=2.2 / \mathrm{IQR}=1.5-3.5)$ than those who reported having received $(\mathrm{Md}=2.0 / \mathrm{IQR}=1.9-3.1)$ or not $(\mathrm{Md}=2.0 / \mathrm{IQR}=1.0-3.0)$. Those who reported not knowing whether they received VAR had a higher income $(\mathrm{Md}=2.5 / \mathrm{IQR}=1.5-3.9)$ than those who reported having received $(\mathrm{Md}=2.0 / \mathrm{IQR}=1.0-2.5)$ or not $(\mathrm{Md}=2.0 / \mathrm{IQR}=1.0-3.0)$. There was no income difference between those who reported having received $(\mathrm{Md}=2.0 / \mathrm{IQR}=1.5-$ $3.0)$, not receiving $(\mathrm{Md}=2.0 / \mathrm{IQR}=1.0-2.5)$ or not knowing whether they received DTaP $(\mathrm{Md}=2.0 / \mathrm{IQR}=1.5-3.0)$.

There was no statistically significant association between income and reported vaccination status for: IIV, PCV13, PP23V, Tdap, Rubella, RZV, MMR, HPV and BCG.

Those who received Hib had a higher educational level $(100 \%$ with complete high school education or above) than those who reported not having received $(46 \%)$ or not knowing whether they received $(22.7 \%)(P=0.04007$, Fisher's exact test $)$. Those who received HepA had a higher education level (78\% with complete primary education or higher) than those who reported not having received $(52 \%)$ or not knowing whether they received $(61 \%)$ $(P=0.0148$, Fisher's exact test $)$.

There was no statistically significant association between level of education and reported vaccination status for: IIV, PCV13, PP23V, Tdap, HepB, MenACWY, VAR, Rubella, RZV, MMR, DTaP, HPV and BCG.

It was not possible to establish correlation between vaccination status and ethnicity or between vaccination status and gender.

Reports of vaccination reactions were rare, with $93.6 \%$ of the patients reporting never having had a vaccine reaction. It was not possible to establish correlation between vaccine reaction and ethnicity $(P=0.5477)$ or between vaccine reaction and diagnosis $(P=1.0000)$.

\section{DISCUSSION}

Since most IBD patients will receive immunosuppressive therapy at some point, either short-term (e.g. corticosteroids) or long-term (e.g. biological agents and immunomodulators), vaccination history should be verified to guarantee that all recommended vaccines were taken to reduce the risk of preventable infections.

Clinical guidelines recommend routine vaccination of patients with IBD, with the exception of live attenuated vaccines. In addition, it is recommended to recover the vaccination history at the time of IBD diagnosis for adults and children ${ }^{(9,10)}$.

The use of biological agents may interfere with the vaccine response, therefore vaccination is recommended soon after the diagnosis of $\mathrm{CD}$ or $\mathrm{UC}$, regardless of the use and preferably prior to the use of immunobiologicals. However, inactivated virus vaccines can be administered even in immunosuppressed and vaccination is preferred over non-vaccination in such cases ${ }^{(11)}$.
Previous studies showed that the rate of immunization is low. It is fundamentally important that those patients are advised of the importance of vaccination and followed up to receive appropriate vaccination $^{(11-13)}$.

There is, therefore, a demand for checking the vaccination status of patients in each specialized service to guide the institutions on the need of accessing and increasing the vaccination coverage to the recommended levels.

In this study, demographic data revealed the predominance of females and white patients, corroborating findings of previous studies and indicating that the sample is representative of the population. The mean age was 46 years, which also coincides with several other studies ${ }^{(14,15)}$. Level of education and employment status characterized a population with low and medium level education and low employability. Regarding nutritional characterization, the BMI average demonstrated a tendency to overweight.

Slightly over than half of the patients were diagnosed with $\mathrm{CD}$, of which about $40 \%$ were or had been using biological agents.

In this sample, although taken from a specialized service and with routine follow-up of guidelines, low vaccination rates were found or at least a small declared awareness and documentation of vaccination (vaccination record card and medical record). It is worth mentioning the coverage of more than $70 \%$ for IIV only, which is probably a reflection of recent mass vaccination campaigns associated with local outbreaks. Whether due to inadequate counseling or lack of knowledge about the physical effects of vaccines, this is of particular relevance when observing their recurrence in studies of vaccine profiles ${ }^{(16-18)}$.

The practice of recovering the vaccine history at the time of the diagnosis of IBD, which was expected to be already established, was disappointing, demonstrating the need for positive training of the team to do so.

These data are similar to those of Melmed et al., which in a study with 169 adults with IBD found out that from the total sample, $28 \%$ received the IIV, only $9 \%$ received pneumococcal vaccine and $45 \%$ received tetanus vaccine ${ }^{(13)}$.

The data on the vaccination status according to the diagnosis demonstrated a difference in PCV13, Tdap and HepB, in which the rate of patients diagnosed with $\mathrm{CD}$ who reported having received the vaccine was higher than those diagnosed with UC. According to the data from the study, there was greater use of biological agents in patients with CD (96.6\% of the cases), and therefore, greater orientation regarding the vaccination status in these patients.

Among the patients who are or have already been treated with biological agents, the vast majority reported having received IIV, however a minority reported having received PP23V vaccine.

Among the patients who had never been treated with biological agents, we had a similar picture. What we can infer from this information is the efficiency and importance of proper vaccination counseling since annual Flu vaccination is widely publicized and most patients remember to have taken and even carried the proof of vaccination with them. These findings highlight the need for a formal and structured review of vaccination as a whole.

The level of education and the average income in minimum wages cannot be considered as determining factors in the vaccine profile of the patients in this study. By the heterogeneity of the correlation results it can be stated that the social factors related to the patients, such as income and education did not influence the performance of most vaccines, since they are part of the official 
compulsory vaccination schedule offered by the Brazilian health system for infants and children. For the most recently included vaccines in the schedule and the ones exclusively recommended for adults the awareness rates seem to rely on the effectiveness of the caretakers' instructions.

According to Lu et al., the reasons why patients do not get vaccinated include: fear of side effects and complications, presuming that vaccines are ineffective or may lead to recurrence of IBD symptoms and unawareness of the indication, either by an assumption that vaccination isn't needed or by the lack of proper guidance from their physician ${ }^{(12)}$.

In the present study, except for the vaccine reaction, this information was not considered. The majority $(93.6 \%)$ reported never having had a vaccine reaction, corroborating studies that questioned exacerbated vaccine reactions in patients with $\operatorname{IBD}^{(4,19)}$, and ratifying the indication of vaccines. However, other factors that have been shown an influence to the patient's response to medical guidance should be taken into account in the preparation of future vaccination guidance documents.

There was no case of inadvertent vaccination with live virus vaccine, which could be a concern in our country where there are endemic areas for yellow fever.

We couldn't find any similar Latin American publication in the main internet databases. We believe this study to be one of the few detailing the vaccination status of IBD patients in South America.

Three points can be considered as limitations to our study. Since the information was acquired by the application of questionnaires and not by collecting official medical records, it is subjective and do not depict the actual vaccination coverage for IBD patients. Also, the study population was selected by convenience sampling in the outpatient clinic of a tertiary care hospital, thus having an increased amount of comorbidities. Lastly, because this study was unicentric and we couldn't find similar Brazilian publications, it is not possible to assert that it represents the entire Brazilian IBD population.

The main contribution of our study is evidencing the rates of immunization in IBD patients along with the patients' awareness of their own vaccination status, in which can be considered one of the first publications of the kind in Latin America.

\section{CONCLUSION}

Although being a specialized university service, a reference in the treatment of IBD, with a permanent orientation to follow the guidelines regarding the immunization of the patients, vaccination coverage, awareness rates and documentation of the vaccination status proved to be below the desirable level. Vaccination and recovery of the immunization history is recommended immediately after the diagnosis of CD or UC, regardless of the use of immunobiological agents. Those findings support the need of implementing hospital guidelines and constantly verifying its application by the multidisciplinary team in specialized services in IBD.

\section{Authors' contribution}

Strasse KL, Jamur CM, Marques J, Kim MSM: data collection, writing and revising. Petterle RR: statistical analysis. Amarante HMBS: orientation and revising.

\section{Orcid}

Karin Lye auf der Strasse. Orcid: 0000-0002-4103-793X.

Carmen Mayanna Jamur. Orcid: 0000-0002-2364-2722.

Janaina Marques. Orcid: 0000-0003-4312-2967.

Mirian Su Mi Kim. Orcid: 0000-0002-7699-377X.

Ricardo Rasmussen Petterle. Orcid: 0000-0001-7735-1077.

Heda Maria Barska dos Santos Amarante. Orcid: 0000-00017449-1138.

Strasse KL, Jamur CM, Marques J, Kim MSM, Petterle RR, Amarante HMBS. Situação vacinal de pacientes com doença inflamatória intestinal. Arq Gastroenterol. 2019;56(2):124-30.

RESUMO - Contexto - No tratamento de doenças inflamatórias intestinais (DII) são usados imunossupressores e agentes biológicos, o que aumenta o risco de infecções pela alteração da imunidade celular e humoral. A prevenção de algumas dessas infecções pode ser feita pela vacinação, entretanto pacientes com DII apresentam baixas taxas de cobertura vacinal. Objetivo - Analisar a situação vacinal de pacientes com DII e comparar com a recomendação vigente na literatura para verificar se os esquemas de imunização estão sendo corretamente aplicados nessa população. Métodos - Estudo transversal analítico com 239 pacientes com DII em acompanhamento no Serviço de Gastroenterologia do Hospital de Clínicas da Universidade Federal do Paraná, os quais foram submetidos a um questionário sobre dados demográficos relevantes e sobre a situação vacinal. Resultados - A taxa de pacientes que declarou não ter conhecimento de sua situação vacinal é alta - entre 34,3\% (dTpa) e 52\% (meningocócica) - com exceção das vacinas influenza, hepatite B e HPV. As vacinas com maior taxa de pacientes que declararam ter recebido a vacina são influenza (72,4\%), BCG (55,3\%), hepatite B $(48,3 \%)$, tríplice viral $(43,8 \%)$ e DTPa (43\%). As vacinas com menor taxa de pacientes que declararam ter recebido a vacina são Haemophilus influenza $\mathrm{b}(0,8 \%)$, herpes zoster $(2,1 \%)$ e HPV $(3,4 \%)$. Pacientes que fazem ou já fizeram tratamento com agentes biológicos têm melhor cobertura vacinal das vacinas para influenza ( $81 \%)$ e PP23V (25,9\%), além de maior conhecimento sobre o estado vacinal para essas vacinas. Conclusão - Apesar de se tratar de um serviço especializado ligado a um hospital universitário, a cobertura vacinal e o conhecimento dos pacientes sobre as vacinas estão abaixo do desejado. A recuperação do histórico vacinal e a recomendação das vacinas necessárias devem ser realizadas logo após o diagnóstico de DII, independentemente do uso de agentes biológicos. Esses achados indicam a necessidade da criação e monitoramento constante da aplicação de um protocolo pela equipe multidisciplinar de serviços especializados em DII.

DESCRITORES - Doenças inflamatórias intestinais. Doença de Crohn. Proctocolite. Vacinação, uso terapêutico. Imunização. 


\section{REFERENCES}

1. Malik TA. Inflammatory Bowel Disease. Surg Clin North Am. 2015;95:1105-22

2. Braunwald E, Harrison TR, editors. Harrison's principles of internal medicine. 15. ed. New York: McGraw-Hill; 2001.

3. Wasan SK, Coukos JA, Farraye FA. Vaccinating the inflammatory bowel disease patient: Deficiencies in gastroenterologists knowledge. Inflamm Bowel Dis. 2011;17:2536-40.

4. Rahier JF, Magro F, Abreu C, Armuzzi A, Ben-Horin S, Chowers Y, et al. Second European evidence-based consensus on the prevention, diagnosis and management of opportunistic infections in inflammatory bowel disease. J Crohns Colitis. 2014;8:443-68.

5. Chaudrey K, Salvaggio M, Ahmed A, Mahmood S, Ali T. Updates in vaccination: Recommendations for adult inflammatory bowel disease patients. World $J$ Gastroenterol. 2015;21:3184-96.

6. Luz KR da, Souza DCC de, Ciconelli RM. Vacinação em pacientes imunossuprimidos e com doenças reumatológicas auto-imunes. Rev Bras Reumatol. 2007;47:106-13.

7. Carrera E. Efficacy of the vaccination in inflammatory bowel disease. World $\mathrm{J}$ Gastroenterol. 2013;19:1349.

8. R Core Team (2018). R: A language and environment for statistical computing R Foundation for Statistical Computing, Vienna, Austria. Available online at https://www.R-project.org/.

9. Sands BE, Cuffari C, Katz J, Kugathasan S, Onken J, Vitek C, et al. Guidelines for Immunizations in Patients With Inflammatory Bowel Disease. Inflamm Bowe Dis. 2004;10:677-92.

10. Wasan SK, Baker SE, Skolnik PR, Farraye FA. A Practical Guide to Vaccinating the Inflammatory Bowel Disease Patient. Am J Gastroenterol. 2010;105:1231-8.

11. Nguyen GC, Devlin SM, Afif W, Bressler B, Gruchy SE, Kaplan GG, et al. Defining Quality Indicators for Best-Practice Management of Inflammatory Bowel Disease in Canada. Can J Gastroenterol Hepatol 2014·28·275-85.
12. Lu Y, Bousvaros A. Immunizations in children with inflammatory bowel disease treated with immunosuppressive therapy. Gastroenterol Hepatol. 2014;10 355-63.

13. Melmed GY, Ippoliti AF, Papadakis KA, Tran TT, Birt JL, Lee SK, et al. Patients with inflammatory bowel disease are at risk for vaccine-preventable illnesses. Am J Gastroenterol. 2006;101:1834-40.

14. Niriella MA, De Silva AP, Dayaratne AH, Ariyasinghe MH, Navarathne MM, Peiris RS, et al. Prevalence of inflammatory bowel disease in two districts of Sri Lanka: a hospital based survey. BMC Gastroenterology. 2010;10(1):32. [Internet] [Cited 2018 Sep 20]. Available from: http://bmcgastroenterol.biomedcentral.com/ articles/10.1186/1471-230X-10-32

15. Pittet V, Juillerat P, Mottet C, Felley C, Ballabeni P, Burnand B, et al. Cohort Profile: The Swiss Inflammatory Bowel Disease Cohort Study (SIBDCS). Int J Epidemiol. 2009;38:922-31.

16. Malhi G, Rumman A, Thanabalan R, Croitoru K, Silverberg MS, Hillary Steinhart A, et al. Vaccination in Inflammatory Bowel Disease Patients: Attitudes, Knowledge, and Uptake. J Crohns Colitis. 2015;9:439-44.

17. Gupta A, Macrae FA, Gibson PR. Vaccination and screening for infections in patients with inflammatory bowel disease: a survey of Australian gastroenterologists: Inflammatory bowel disease. Intern Med J. 2011;41:462-7.

18. Jung YS, Park JH, Kim HJ, Cho YK, Sohn CI, Jeon WK, et al. Insufficient Knowledge of Korean Gastroenterologists Regarding the Vaccination of Patients with Inflammatory Bowel Disease. Gut Liver. 2014;8:242-7.

19. Dreskin SC, Halsey NA, Kelso JM, Wood RA, Hummell DS, Edwards KM, et al. International Consensus (ICON): allergic reactions to vaccines. World Allergy Organ J. 2016;9(1):32. [Internet]. [Cited 2018 Sep 20]. Available from: http:// waojournal.biomedcentral.com/articles/10.1186/s40413-016-0120-5 